\title{
ÉPOCA DE SEMEADURA DA SOJA PARA A REGIÃO DE DOURADOS - MS, COM BASE NA DEFICIÊNCIA HÍDRICA E NO FOTOPERÍODO
}

\author{
CARLOS R. FIETZ ${ }^{1}$, MARCO A. S. RANGEL ${ }^{2}$
}

RESUMO: O objetivo deste trabalho foi definir a época de semeadura da soja para a região de Dourados - MS, em função da deficiência hídrica e do fotoperíodo. Foram avaliadas três épocas de semeadura (15 de outubro, 15 de novembro e 15 de dezembro), utilizando-se de série de 20 anos de dados. A deficiência hídrica da soja foi estimada por meio de balanço hídrico-climatológico diário sequencial, e o fotoperíodo foi calculado em função da latitude e da data. $\mathrm{O}$ atraso da semeadura reduziu o déficit hídrico. Analisando-se conjuntamente os fatores déficit hídrico e fotoperíodo, concluiu-se que semeaduras da soja em novembro são mais indicadas para a região de Dourados.

PALAVRAS-CHAVE: Glycine max, balanço hídrico, estresse hídrico.

\section{SOYBEAN SOWING TIME FOR THE REGION OF DOURADOS, MS, BRAZIL BASED ON WATER DEFICIT AND PHOTOPERIOD}

\begin{abstract}
The aim of this work was to evaluate the influence of water deficit and photoperiod on the development and in the grain yield of soybean, at three sowing times (October $15^{\text {th }}$, November $15^{\text {th }}$ and December $15^{\text {th }}$ ) in Dourados, Mato Grosso do Sul State, Brazil. The work was based on meteorological data of 20 years. The soybean water deficiency was calculated through a daily sequential water balance. The photoperiod was determined through the latitude and the date. The water deficit decreased with the sowing time delay. Based on water deficit and photoperiod, the soybean sowing time in Dourados should be in November.
\end{abstract}

KEYWORDS: Glycine max, water balance, water stress.

\section{INTRODUÇÃO}

A região de Dourados, Mato Grosso do Sul, situa-se numa das principais áreas de produção agrícola do Brasil, sendo cultivados anualmente em torno de um milhão de hectares com soja (LEVANTAMENTO..., 2006). A época de semeadura da soja indicada pelo Zoneamento Agrícola para a região de Dourados é muito ampla, variando de meados de outubro ao final de dezembro (ZONEAMENTO..., 2005). De modo geral, o período preferencial para a semeadura da soja em toda a região Centro-Oeste vai de 20 de outubro a 10 de dezembro, mas as realizadas em novembro proporcionam maiores produtividades (TECNOLOGIAS..., 2003).

Várias dessas lavouras de soja são semeadas em outubro, visando a possibilitar a semeadura do milho segunda safra, cujo limite é a primeira quinzena de março. No entanto, dois outros fatores que afetam diretamente o desenvolvimento e a produtividade da soja devem ser considerados na definição da época de semeadura: a deficiência hídrica e o fotoperíodo.

A soja é sensível à duração das horas de luz do dia, florescendo quando o comprimento dos dias é inferior a determinado valor, denominado fotoperíodo crítico (CÂMARA, 1998). No entanto, segundo RODRIGUES et al. (2001), a sensibilidade fotoperiódica da soja varia com o genótipo e, nas cultivares sensíveis, a resposta ao fotoperíodo é quantitativa e não absoluta, o que significa que a floração ocorrerá de qualquer modo. De acordo com CÂMARA (1998), a melhor época teórica de semeadura da soja em qualquer região apta ao seu cultivo situa-se entre 30 ( 21 de novembro) e

\footnotetext{
${ }^{1}$ Eng ${ }^{2}$ Agrícola, Doutor, Embrapa Agropecuária Oeste, Caixa Postal 661, Dourados - MS. Fone: (0XX67) 3416.9700, fietz@cpao.embrapa.br

${ }^{2}$ Eng $^{\mathrm{o}}$ Agrícola, Doutor, Embrapa Mandioca e Fruticultura Tropical, Cruz das Almas - BA.

Recebido pelo Conselho Editorial em: 5-11-2007
}

Aprovado pelo Conselho Editorial em: 21-1-2009 
45 dias (6 de novembro) antes do solstício de verão (21 de dezembro), pois possibilita tempo suficiente para a planta desenvolver-se com altura e porte compatíveis com elevada produtividade e colheita mecânica.

As necessidades hídricas da soja para a obtenção do máximo rendimento variam entre 450 e $850 \mathrm{~mm}$ por ciclo e aumentam com o desenvolvimento da planta, atingindo o máximo durante a floração e o enchimento de grãos, decrescendo após esse estádio (TECNOLOGIAS..., 2003). Nas condições edafoclimáticas da região de Dourados, FIETZ \& URCHEI (2002) verificaram que ocorreu deficiência hídrica na soja em todos os subperíodos, em todas as safras e épocas de semeadura avaliadas. MATZENAUER et al. (1998) observaram que a deficiência hídrica da soja no Planalto Médio do Rio Grande do Sul diminuiu com o atraso da semeadura e que os valores mais elevados de déficit hídrico ocorreram do início da floração ao início do enchimento de grãos. De acordo com MOTA et al. (1996), a cultura da soja necessita de irrigação em todas as regiões climáticas do Rio Grande do Sul, em qualquer época de semeadura e para todos os grupos de maturação e em todos os subperíodos.

Considerando-se a influência do estresse hídrico e do comprimento dos dias no desenvolvimento da soja, realizou-se este trabalho, cujo objetivo foi definir a época mais adequada de semeadura da soja para a região de Dourados - MS, com base na deficiência hídrica e no fotoperíodo.

\section{MATERIAL E MÉTODOS}

O trabalho baseou-se em série de 20 anos de dados de precipitação, de temperatura, de umidade relativa do ar, do número de horas de brilho solar e da velocidade do vento coletados entre outubro de 1979 e março de 1999, na Estação Agrometeorológica da Embrapa Agropecuária Oeste

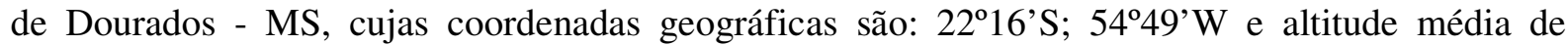
408 m. De acordo com a classificação de Köeppen, o clima da região é o Cwa (mesotérmico úmido, com verão chuvoso).

A deficiência hídrica da soja foi estimada por um balanço hídrico climatológico diário sequencial, por meio do programa computacional SISDA - Sistema de Suporte à Decisão Agrícola (MANTOVANI et al., 1997). Na Tabela 1, estão apresentados os valores de coeficiente de cultivo (FIETZ et al., 2004) e a profundidade do sistema radicular (MANTOVANI et al., 1997) utilizados no cálculo do balanço hídrico. A análise foi realizada para três épocas de semeadura (15 de outubro, 15 de novembro e 15 de dezembro), considerando cultivares de ciclos precoce e médio.

Os estádios de desenvolvimento da soja foram estabelecidos segundo FEHR \& CAVINESS (1977). A duração dos subperíodos da cultura (Tabela 1) foram definidos com base em observações de seis genótipos de ciclo precoce (cultivares BRS 206, EMBRAPA 48, CD 202, BRS 155 e linhagens BR 95-013373 e BR 96-24315) e quatro genótipos de ciclo médio (cultivares BRS 182, CD 205, M-SOY 8001 e linhagem BR 95-008534), apresentados em RANGEL et al. (2005).

A evapotranspiração de referência $\left(\mathrm{ET}_{0}\right)$ foi estimada pelo método Penman-Monteith (ALLEN et al., 1998) e a evapotranspiração da cultura obtida pelo produto da $\mathrm{ET}_{0}$ e o coeficiente de cultivo. O fotoperíodo diário foi calculado em função da latitude e da data (ALLEN et al., 1998).

Os atributos físicos do solo utilizados no cálculo do balanço hídrico estão apresentados na Tabela 2. Esses atributos foram definidos por FIETZ \& URCHEI (2002), com base em curvas de retenção de um Latossolo Vermelho distroférrico álico muito argiloso, uma das principais unidades pedológicas da região. 
TABELA 1. Duração dos subperíodos da soja (dias) para cultivares de ciclo precoce e médio, com os respectivos coeficientes de cultivo $\left(\mathrm{K}_{\mathrm{c}}\right)$ e profundidade efetiva do sistema radicular $(\mathrm{P})$, em três épocas de semeadura. Duration of soybean growth stage (days), crop coefficients and effective root depth of early and mid-cycle cultivars in three sowing dates.

\begin{tabular}{|c|c|c|c|c|c|}
\hline \multirow{2}{*}{ Subperíodo* } & \multicolumn{3}{|c|}{ Semeadura } & \multirow{2}{*}{$\mathrm{K}_{\mathrm{c}}$} & \multirow{2}{*}{$\mathrm{P}(\mathrm{m})$} \\
\hline & $15-10$ & $15-11$ & $15-12$ & & \\
\hline \multicolumn{6}{|l|}{ Ciclo precoce } \\
\hline $\mathrm{S}$ a V2 & 15 & 13 & 14 & 0,39 & 0,15 \\
\hline V2 a R1 & 26 & 31 & 29 & 1,09 & 0,30 \\
\hline R1 a R5 & 28 & 19 & 22 & 1,61 & 0,40 \\
\hline R5 a R7 & 34 & 34 & 29 & 1,28 & 0,40 \\
\hline \multicolumn{6}{|l|}{ Ciclo médio } \\
\hline $\mathrm{S}$ a V2 & 15 & 13 & 15 & 0,39 & 0,15 \\
\hline V2 a R1 & 36 & 37 & 32 & 1,09 & 0,30 \\
\hline R1 a R5 & 31 & 30 & 25 & 1,61 & 0,40 \\
\hline R5 a R7 & 36 & 31 & 27 & 1,28 & 0,40 \\
\hline \multicolumn{6}{|c|}{$\begin{array}{l}\text { *S - semeadura; V2 - segundo nó; R1 - início do florescimento; R5 - início do enchimento de grãos, e R7 - maturação } \\
\text { fisiológica }\end{array}$} \\
\hline \multicolumn{6}{|c|}{$\begin{array}{l}\text { TABELA 2. Umidade do solo na capacidade de campo }\left(U_{C C}\right) \text {, no ponto de murcha }\left(U_{P M}\right) \text { e } \\
\text { densidade do solo }\left(D_{s}\right) \text {. Soil moisture at field capacity }\left(\mathbf{U}_{\mathbf{C C}}\right) \text {, permanent wilting } \\
\text { point }\left(\mathbf{U}_{\mathbf{P M}}\right) \text { and soil density }\left(\mathbf{D}_{\mathbf{s}}\right) \text { in two soil depth. }\end{array}$} \\
\hline Profundidade $(\mathrm{m})$ & $\mathrm{U}_{\mathrm{CC}}$ & & $\mathrm{U}_{\mathrm{PM}}\left(\mathrm{g} \mathrm{g}^{-1}\right)$ & & $\left.\mathrm{cm}^{-3}\right)$ \\
\hline $0,00-0,20$ & & & 0,24 & & \\
\hline $0,21-0,40$ & & & 0,26 & & \\
\hline
\end{tabular}

\section{RESULTADOS E DISCUSSÃO}

Houve deficiência hídrica em todos os subperíodos da soja, em todos os anos agrícolas e nas três épocas de semeadura avaliadas (Tabelas 3 e 4). Esses resultados confirmam que a irrigação da soja na região de Dourados, em caráter complementar, é tecnicamente justificada, devido aos altos índices de deficiência hídrica que geralmente ocorrem na safra de verão (FIETZ \& URCHEI, 2002).

As semeaduras realizadas em novembro e dezembro proporcionaram, na maior parte dos anos, menor deficiência hídrica média (Tabelas 3 e 4). Para as cultivares de ciclo precoce (Tabela 3), em 18 safras das 20 analisadas (90\%), houve maior déficit hídrico em todo o ciclo da cultura, quando a semeadura ocorreu em outubro. Observou-se, ainda, que, em 14 safras (70\%), a menor deficiência hídrica foi verificada na semeadura de dezembro.

A época de semeadura também teve grande influência no déficit hídrico da soja de ciclo médio (Tabela 4). Em 16 safras (80\%), foi verificada maior deficiência hídrica no ciclo completo da cultura na semeadura em outubro e em quase a totalidade das safras $(85 \%)$ houve menor déficit hídrico na semeadura em dezembro.

Analisando-se apenas o período crítico da soja, do início da floração até o início do enchimento de grãos (R1-R5), verificou-se que o retardamento da semeadura também reduziu a deficiência hídrica. Tanto para as cultivares de ciclo precoce (Tabela 3), quanto para as de ciclo médio (Tabela 4), em 11 safras (55\%), houve maior deficiência hídrica na semeadura da soja realizada em outubro. Observou-se, também, que, em 18 (90\%) e 19 safras (95\%), para cultivares de ciclos precoce e médio, respectivamente, a semeadura em dezembro proporcionou menor deficiência hídrica.

A menor deficiência hídrica nas semeaduras de novembro e, principalmente, dezembro devese aos estádios da fase reprodutiva da soja, com maior exigência hídrica, ocorrerem em fevereiro e 
março, meses de menor demanda de água para o processo de transpiração que dezembro e janeiro. Resultados similares foram obtidos por MOTA et al. (1996) e MATZENAUER et al. (1998) com a cultura da soja no Rio Grande do Sul.

As relações entre o fotoperíodo da região de Dourados e a duração dos subperíodos das cultivares de soja estão apresentadas na Figura 1. Na semeadura de 15 de outubro (Figuras 1a e 1b), o florescimento (R1) tende a ocorrer quando o fotoperíodo se encontra ainda em ascensão. Nessa época de semeadura, a maior parte do período vegetativo ocorre quando o comprimento médio do dia é inferior ao fotoperíodo crítico, cuja duração para a região de Dourados é estimada em torno de 13 horas (CÂMARA, 1998). Esse fato, associado a períodos de altas temperaturas, que geralmente ocorrem no período da safra de soja, aumenta o risco de florescimento precoce. Segundo CÂMARA et al. (1997), fotoperíodos curtos ou altas temperaturas favorecem a redução do tempo necessário para o florescimento, resultando em plantas de porte baixo e poucos nós, fatores que afetam diretamente a produtividade.

Quando a semeadura é realizada em 15 de novembro (Figuras 1c e 1d), os parâmetros de fotoperíodo mudam completamente em relação aos de 15 de outubro, ou seja, a soja tem seu crescimento vegetativo totalmente dentro de período em que o comprimento médio do dia se encontra acima do fotoperíodo crítico. Essa condição é considerada ótima para a soja, pois possibilita que as plantas atinjam seu porte máximo com o maior número possível de nós.

No caso da semeadura mais tardia, em 15 de dezembro (Figuras 1e e 1f), as condições fotoperiódicas para o crescimento vegetativo encontram-se ainda favoráveis. Entretanto, como a data da semeadura está muito próxima ao solstício de verão, o período favorável, acima do fotoperíodo crítico, tem duração bem menor do que ocorre quando a semeadura é realizada em 15 de novembro, o que pode provocar a indução precoce do florescimento em maior ou menor intensidade, dependendo da sensibilidade da cultivar.

TABELA 3. Estimativa da deficiência hídrica $(\mathrm{mm})$ da soja, cultivares de ciclo precoce, nos subperíodos compreendidos entre a semeadura (S) e o início do florescimento (R1); R1 e o início do enchimento de grãos (R5), e R5 e a maturação fisiológica (R7). Estimate of water deficit $(\mathrm{mm})$ in early-cycle soybean, during growth stages sowing (S) to beginning bloom (R1); R1 to beginning seed (R5) and R5 = beginning maturity (R7).

\begin{tabular}{|c|c|c|c|c|c|c|c|c|c|c|c|c|}
\hline \multirow{3}{*}{$\begin{array}{c}\text { Ano } \\
\text { Agrícola }\end{array}$} & \multicolumn{12}{|c|}{ Época de Semeadura } \\
\hline & \multicolumn{4}{|c|}{15 de outubro } & \multicolumn{4}{|c|}{15 de novembro } & \multicolumn{4}{|c|}{15 de dezembro } \\
\hline & S a R1 & R1 a R5 & 25 a R7 & S a R7 & $\mathrm{S}$ a R1 & R1 a R & $\overline{\mathrm{R} 5}$ a R & S a R7 & $\mathrm{S}$ a R1 & R1 a R5 & 25 a $\mathrm{R} 7$ & S a R7 \\
\hline $1979 / 80$ & 63,4 & 75,1 & 114,5 & 253,0 & 31,0 & 104,4 & 77,8 & 213,2 & 86,2 & 43,5 & 76,1 & 205,8 \\
\hline $1980 / 81$ & 44,6 & 116,1 & 30,4 & 191,1 & 52,6 & 27,6 & 80,2 & 160,4 & 14,9 & 68,8 & 83,5 & 167,2 \\
\hline $1981 / 82$ & 29,4 & 53,2 & 90,6 & 173,2 & 13,8 & 97,0 & 58,0 & 168,8 & 73,2 & 40,6 & 14,5 & 128,3 \\
\hline $1982 / 83$ & 22,5 & 82,1 & 108,7 & 213,3 & 36,2 & 102,2 & 53,2 & 191,6 & 71,6 & 42,8 & 28,7 & 143,1 \\
\hline $1983 / 84$ & 34,3 & 128,3 & 68,5 & 231,1 & 57,8 & 62,3 & 74,7 & 194,8 & 32,6 & 68,0 & 119,8 & 220,4 \\
\hline $1984 / 85$ & 40,7 & 59,6 & 112,9 & 213,2 & 33,7 & 87,0 & 133,4 & 254,1 & 80,7 & 106,0 & 34,2 & 220,9 \\
\hline $1985 / 86$ & 98,5 & 204,9 & 130,0 & 433,4 & 161,3 & 98,9 & 41,2 & 301,4 & 67,2 & 43,5 & 66,1 & 176,8 \\
\hline $1986 / 87$ & 67,3 & 48,4 & 101,9 & 217,6 & 27,7 & 76,9 & 53,7 & 158,3 & 51,1 & 41,2 & 96,7 & 189,0 \\
\hline $1987 / 88$ & 52,0 & 107,9 & 68,5 & 228,4 & 47,0 & 67,3 & 79,3 & 193,6 & 38,0 & 85,1 & 29,7 & 152,8 \\
\hline $1988 / 89$ & 71,5 & 146,6 & 37,4 & 255,5 & 81,5 & 12,4 & 46,2 & 140,1 & 13,6 & 47,3 & 49,4 & 110,3 \\
\hline $1989 / 90$ & 42,4 & 73,3 & 45,7 & 161,4 & 43,3 & 15,8 & 115,9 & 175,0 & 18,7 & 115,5 & 144,7 & 278,9 \\
\hline $1990 / 91$ & 27,8 & 155,8 & 157,6 & 341,2 & 105,0 & 100,7 & 110,3 & 316,0 & 95,9 & 61,7 & 134,9 & 292,5 \\
\hline $1991 / 92$ & 75,2 & 79,0 & 148,0 & 302,2 & 37,5 & 100,8 & 133,4 & 271,7 & 104,0 & 80,4 & 56,2 & 240,6 \\
\hline $1992 / 93$ & 46,7 & 100,5 & 143,7 & 290,9 & 70,9 & 106,0 & 100,8 & 277,7 & 87,4 & 56,1 & 83,3 & 226,8 \\
\hline $1993 / 94$ & 67,7 & 92,7 & 157,8 & 318,2 & 45,7 & 136,4 & 58,8 & 240,9 & 95,7 & 50,5 & 88,2 & 234,4 \\
\hline $1994 / 95$ & 33,8 & 138,3 & 52,6 & 224,7 & 78,7 & 21,5 & 77,3 & 177,5 & 23,0 & 51,8 & 109,5 & 184,3 \\
\hline $1995 / 96$ & 61,1 & 170,9 & 60,1 & 292,1 & 88,4 & 65,4 & 28,8 & 182,6 & 26,5 & 31,4 & 40,8 & 98,7 \\
\hline $1996 / 97$ & 34,3 & 92,2 & 36,6 & 163,1 & 35,0 & 42,0 & 45,1 & 122,1 & 16,4 & 43,8 & 100,7 & 160,9 \\
\hline $1997 / 98$ & 28,9 & 60,8 & 166,0 & 255,7 & 63,2 & 122,4 & 69,1 & 254,7 & 108,3 & 35,5 & 64,1 & 207,9 \\
\hline $1998 / 99$ & 67,3 & 99,4 & 95,2 & 261,9 & 41,0 & 48,4 & 91,0 & 180,4 & 75,2 & 32,2 & 68,0 & 175,4 \\
\hline Média & 50,5 & 104,3 & 96,3 & 251,1 & 57,6 & 74,8 & 76,4 & 208,7 & 59,0 & 57,3 & 74,5 & 190,8 \\
\hline
\end{tabular}


TABELA 4. Estimativa da deficiência hídrica $(\mathrm{mm})$ da soja, em cultivares de ciclo médio, nos subperíodos compreendidos entre a semeadura (S) e o início do florescimento (R1); R1 e o início do enchimento de grãos (R5), e R5 e a maturação fisiológica (R7). Estimate of water deficit $(\mathrm{mm})$ in mid-cycle soybean, during growth stages sowing (S) to beginning bloom (R1); R1 to beginning seed (R5) and R5 = beginning maturity (R7).

\begin{tabular}{|c|c|c|c|c|c|c|c|c|c|c|c|c|}
\hline \multirow{3}{*}{$\begin{array}{c}\text { Ano } \\
\text { Agrícola }\end{array}$} & \multicolumn{12}{|c|}{ Época de Semeadura } \\
\hline & \multicolumn{4}{|c|}{15 de outubro } & \multicolumn{4}{|c|}{15 de novembro } & \multicolumn{4}{|c|}{15 de dezembro } \\
\hline & S a R1 & R1 a R5 & R5 a R7 & S a R7 & S a R1 & R1 a R5 & 25 a R7 & S a R7 & $\mathrm{S}$ a R1 & $\mathrm{R} 1 \mathrm{a}$ R5 & $\mathrm{R} 5 \mathrm{a} \mathrm{R}$ & S a R7 \\
\hline $1979 / 80$ & 73,7 & 75,0 & 125,3 & 274,0 & 35,4 & 146,7 & 53,2 & 235,3 & 89,0 & 78,7 & 56,0 & 223,7 \\
\hline $1980 / 81$ & 54,4 & 111,1 & 46,6 & 212,1 & 55,8 & 52,0 & 79,7 & 187,5 & 15,8 & 95,7 & 68,5 & 180,0 \\
\hline $1981 / 82$ & 39,5 & 60,7 & 106,8 & 207,0 & 23,6 & 144,0 & 15,4 & 183,0 & 77,7 & 35,1 & 9,4 & 122,2 \\
\hline $1982 / 83$ & 43,4 & 93,3 & 89,1 & 225,8 & 56,7 & 108,3 & 36,9 & 201,9 & 66,5 & 48,5 & 27,0 & 142,0 \\
\hline $1983 / 84$ & 60,5 & 116,7 & 68,5 & 245,7 & 61,0 & 81,8 & 113,2 & 256,0 & 34,2 & 107,7 & 88,4 & 230,3 \\
\hline $1984 / 85$ & 126,4 & 255,7 & 75,7 & 457,8 & 37,4 & 175,9 & 69,9 & 283,2 & 97,9 & 108,3 & 19,9 & 226,1 \\
\hline $1985 / 86$ & 86,6 & 97,2 & 43,7 & 227,5 & 190,2 & 88,6 & 48,4 & 327,2 & 62,2 & 39,1 & 73,0 & 174,3 \\
\hline $1986 / 87$ & 83,5 & 92,9 & 85,0 & 261,4 & 58,2 & 66,8 & 61,0 & 186,0 & 45,4 & 65,2 & 87,4 & 198,0 \\
\hline $1987 / 88$ & 104,5 & 113,1 & 31,3 & 248,9 & 52,9 & 89,4 & 61,5 & 203,8 & 40,6 & 80,7 & 33,0 & 154,3 \\
\hline $1988 / 89$ & 51,1 & 81,7 & 92,3 & 225,1 & 81,5 & 38,9 & 52,4 & 172,8 & 15,1 & 59,6 & 42,8 & 117,5 \\
\hline $1989 / 90$ & 64,9 & 188,6 & 120,1 & 373,6 & 44,0 & 88,6 & 133,7 & 266,3 & 38,1 & 128,4 & 112,3 & 278,8 \\
\hline 1990/91 & 95,4 & 110,0 & 154,6 & 360,0 & 137,5 & 132,6 & 117,3 & 387,4 & 89,6 & 108,6 & 99,7 & 297,9 \\
\hline $1991 / 92$ & 52,1 & 168,6 & 116,2 & 336,9 & 66,1 & 189,0 & 64,5 & 319,6 & 113,8 & 104,9 & 24,7 & 243,4 \\
\hline $1992 / 93$ & 101,8 & 108,6 & 113,2 & 323,6 & 91,2 & 148,8 & 72,8 & 312,8 & 87,0 & 73,3 & 62,7 & 223,0 \\
\hline $1993 / 94$ & 101,8 & 108,6 & 113,2 & 323,6 & 65,4 & 134,0 & 52,4 & 251,8 & 93,9 & 59,4 & 83,2 & 236,5 \\
\hline $1994 / 95$ & 60,7 & 122,3 & 52,9 & 235,9 & 79,2 & 76,6 & 75,5 & 231,3 & 28,1 & 91,6 & 78,3 & 198,0 \\
\hline $1995 / 96$ & 114,9 & 156,7 & 32,8 & 304,4 & 107,0 & 52,4 & 35,0 & 194,4 & 24,8 & 46,2 & 28,1 & 99,1 \\
\hline $1996 / 97$ & 75,0 & 57,2 & 33,9 & 166,1 & 37,9 & 30,0 & 84,1 & 152,0 & 16,1 & 85,1 & 78,1 & 179,3 \\
\hline $1997 / 98$ & 30,4 & 162,2 & 105,4 & 298,0 & 88,7 & 142,4 & 35,4 & 266,5 & 104,9 & 52,3 & 45,3 & 202,5 \\
\hline $1998 / 99$ & 90,2 & 86,2 & 101,3 & 277,7 & 43,9 & 126,1 & 55,0 & 225,0 & 76,7 & 54,8 & 52,1 & 183,6 \\
\hline Média & 75,5 & 118,3 & 85,4 & 279,3 & 70,7 & 105,6 & 65,9 & 242,2 & 60,9 & 76,2 & 58,5 & 195,5 \\
\hline
\end{tabular}

Analisando-se conjuntamente os fatores fotoperíodo e deficiência hídrica, verifica-se que semeaduras da soja em novembro são mais indicadas para a região de Dourados. Os resultados foram similares aos obtidos por VAL et al. (1985) e MOTTA et al. (2002) e confirmam a observação de CÂMARA (1998), de que a melhor época teórica de semeadura da soja, em qualquer região apta, situa-se entre 6 e 30 de novembro. 
(a)

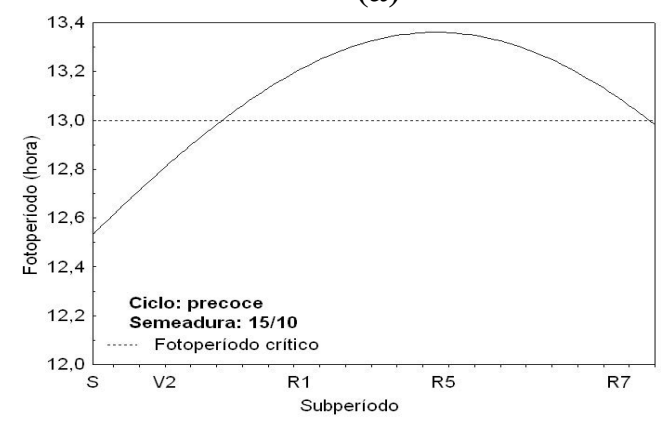

(c)

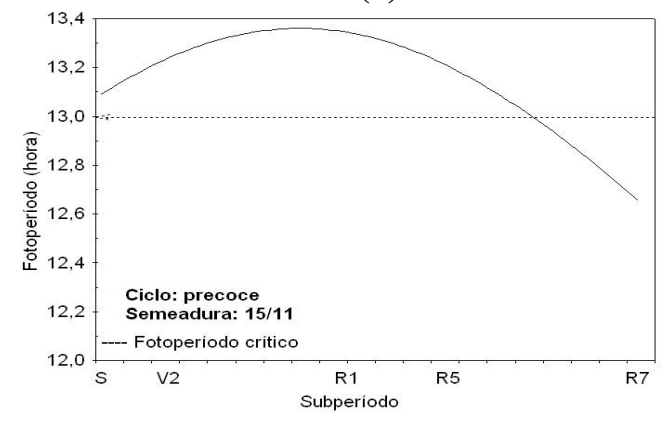

(e)

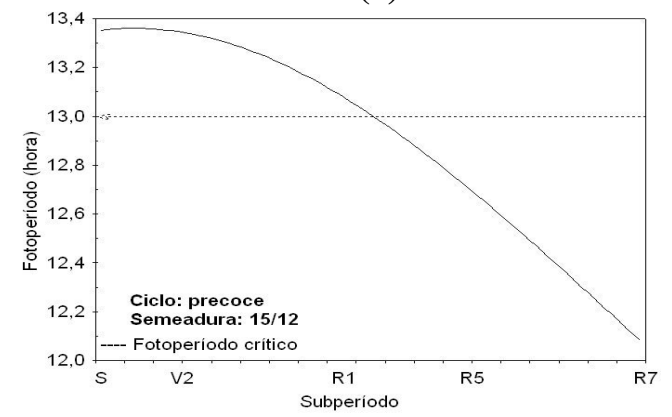

(b)

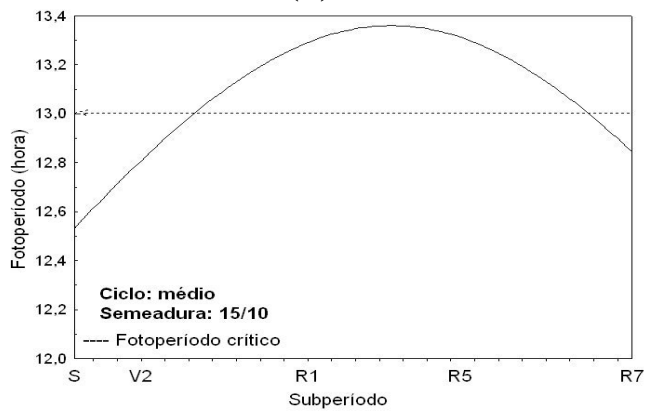

(d)

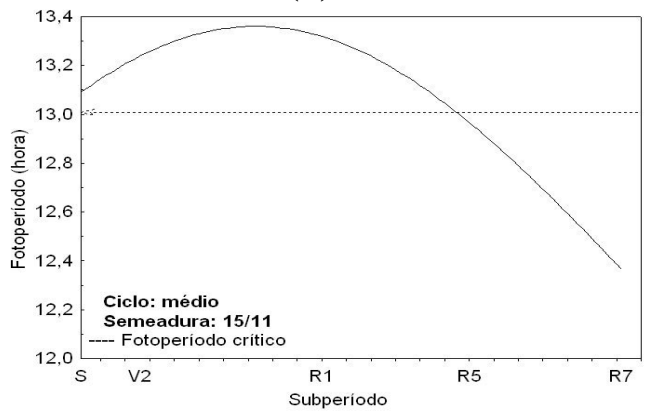

(f)

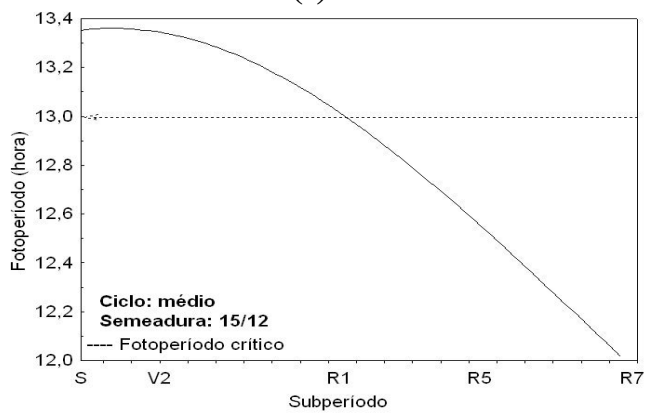

FIGURA 1. Fotoperíodo na região de Dourados - MS, em relação aos subperíodos de cultivares de soja, na semeadura de 15 de outubro, ciclos precoce (a) e médio (b); na semeadura de 15 de novembro, ciclos precoce (c) e médio (d), e na semeadura de 15 de dezembro, ciclos precoce (e) e médio (f). Photoperiod in Dourados region, MS, in relation to soybean growth stages, at 15 October soybean sowing, early (a) and mid-cycle (b), at 15 November soybean sowing, early and (c) and mid-cycle (d), and at 15 December soybean sowing, early (e) and mid-cycle (f).

\section{CONCLUSÕES}

Considerando-se isoladamente o fator deficiência hídrica, as semeaduras da soja em novembro e dezembro são as mais favoráveis para a região de Dourados. Com base no fotoperíodo, a semeadura em novembro apresenta condições mais favoráveis. Analisando-se conjuntamente esses fatores, as semeaduras da soja em novembro são as mais indicadas para a região de Dourados.

\section{REFERÊNCIAS}

ALLEN, R.; PEREIRA, L.S.; RAES, D.; SMITH, M. Crop evapotranspiration: guidelines for computing crop water requirements. Rome: FAO, 1998. 297 p. (Irrigation and Drainage Paper, 56).

CÂMARA, G.M.S. Ecofisiologia da soja e rendimento. In: CÂMARA, G.M.S. Soja: tecnologias da produção. Piracicaba: ESALQ, 1998. p.256-77. 
CÂMARA, G.M.S.; SEDIYAMA, T.; DOURADO-NETO, D.; BERNARDES, M.S. Influence of photoperiod and air temperature on the growth, flowering and maturation of soybean (Glycine max (L.) Merrill). Scientia Agricola, Piracicaba, v.54, n. esp., p.149-54, junho, 1997.

FEHR, W.R.; CAVINESS, C.E. Stages of soybean development. Ames: Iowa State University of Science and Technology, 1977. 11 p. (Special Report, 80).

FIETZ, C.R.; SILVA, F.C.; URCHEI, M.A.; FRIZZONE, J.A. Evapotranspiração da soja na região de Dourados - MS, determinada por lisímetros de pesagem. In: CONGRESSO BRASILEIRO DE ENGENHARIA AGRÍCOLA, 33., 2004, São Pedro. Anais... Campinas: Associação Brasileira de Engenharia Agrícola, 2004. 1 CD-ROM.

FIETZ, C.R.; URCHEI, M.A. Deficiência hídrica da cultura da soja na região de Dourados - MS. Revista Brasileira de Engenharia Agrícola e Ambiental, Campina Grande, v.6, n.2 p.262-5, 2002.

LEVANTAMENTO SISTEMÁTICO DA PRODUÇÃO AGRÍCOLA. Campo Grande: IBGE, Unidade Estadual, dez. 2006. Não paginado.

MANTOVANI, E.C.; COSTA, L.C.; LEAL, B.G. SISDA - Sistema de Suporte à Decisão Agrícola. In: CONGRESSO DE INFORMÁTICA APLICADA À AGROPECUÁRIA E AGROINDÚSTRIA, 1.; WORKSHOP ON SUPPLY CHAIN MANAGEMENT IN AGRIBUSINESS, 1997, Belo Horizonte. Anais... Juiz de Fora: Softex- Agrosoft, 1997. 1 CD-ROM.

MATZENAUER, R.; BARNI, N.A.; MACHADO, F.A.; ROSA, F.S. Análise agroclimática das disponibilidades hídricas para a cultura da soja na região do Planalto Médio do Rio Grande do Sul. Revista Brasileira de Agrometeorologia, Santa Maria, v.6, n.2, p.263-75, 1998.

MOTA, F.S.; AGENDES, M.O.O.; ALVES, E.G.P.; SIGNORINI, E. Análise agroclimática da necessidade de irrigação da soja no Rio Grande do Sul. Revista Brasileira de Agrometeorologia, Santa Maria, v.4, n.1, p.133-8, 1996.

MOTTA, I.S.; BRACCINI, A.L.; SCAPIN, C.A.; INOUE, H.; ÁVILA, M.R.; BRACCINI, M.C.L. Época de semeadura em cinco cultivares de soja. II. Efeito na qualidade fisiológica das sementes. Acta Scientiarum, Maringá, v.24, n.5, p. 1.281-6, 2002.

RANGEL, M.A.S.; GABRIEL, M.; CARDOSO, D.L.; CARDOSO, P.C.; MÜLLER, C. B31: comportamento fenológico da soja semeada em três épocas, na região de Dourados -MS. In: REUNIÃO DE PESQUISA DE SOJA DA REGIÃO CENTRAL DO BRASIL, 27., 2005, Cornélio Procópio. Resumos... Londrina: Embrapa Soja, 2005. p. 97-98. (Documentos, 257).

RODRIGUES, O.; DIDONET, A.D.; LHAMBY, J.C.B.; BERTAGNOLLI, P.F.; LUIZ, J.S. da. Resposta quantitativa do florescimento da soja à temperatura e ao fotoperíodo. Pesquisa Agropecuária Brasileira, Brasília, v.36, n.3, p.431-7, 2001.

TECNOLOGIAS DE PRODUÇÃO DE SOJA - Região Central do Brasil 2004. Londrina: Embrapa Soja; Dourados: Embrapa Agropecuária Oeste; Planaltina: Embrapa Cerrados; Belo Horizonte: EPAMIG; Uberaba: Fundação Triângulo, 2003. 237 p. (Sistemas de Produção, 4).

VAL, W.M.C.; GAUDÊNCIO, C.A.; GARCIA, A. Ensaio sobre época de plantio. In: RESULTADOS DE PESQUISA DE SOJA: 1984/85. Londrina: EMBRAPA-CNPSo, 1985. p.3936. (Documentos, 15).

ZONEAMENTO AGRÍCOLA - Brasil: Mato Grosso do Sul: soja. Brasília - DF: Embrapa; Campinas: CEPAGRI, 2005. Disponível em: <http://orion.cpa.unicamp.br/zonbrasil>. Acesso em: 17 set. 2007. 